\title{
Globalized blended education: securing synergies among far flung universities
}

\author{
Varun Gupta ${ }^{1,2}$ (1)
}

Received: 28 April 2020 / Accepted: 20 April 2021 / Published online: 6 May 2021

(c) The Author(s), under exclusive licence to Springer Nature Switzerland AG 2021

\begin{abstract}
The Coronavirus pandemic (COVID-19) has forced the education stakeholders to adopt online education as a substitute for face to face education despite the varied perceptions about effectiveness of online courses. The goal of this commentary is to leverage collaborations between universities to complement online learning offered by the parent university (university where student is registered for a degree) with the face to face learning offered by the collaborative university (university with low spatial proximity to the student's home where he or she enrolls as exchange student). This helps the student to enhance the value of education in a blended mode (i.e., a mix of online and face to face learning) thereby reducing the psychological distance from online education. The collaboration has several implementation issues, but they could be overcome through active government support at an international level and the establishment of common academic frameworks to assist greater understanding between universities globally, improved flexibility of decision-making at university level and joint recognition of online learning. Long-term collaborations as a "new-normal" practice will be beneficial to transform the educational world into truly virtual single entities. Creating synergies between the competitors would have been a load sharing and responsibility sharing in response to the challenges posed by the virus.
\end{abstract}

Keywords Coronavirus · COVID-19 - Online education · Face to face education · Globalized blended education · Global Partnerships · Universities partnerships

“...True education must correspond to the surrounding circumstances or it is not a healthy growth." -Mahatma Gandhi

Varun Gupta

varun.gupta@usz.edu.pl

1 Instytut Zarzadzania, Uniwersytet Szczeciński, 71-004 Szczecin, Poland

2 Centro de posgrado, Instituto de Iniciativas Empresariales y Empresa Familiar "Conde de Campomanes", Universidad Carlos III de Madrid, 28903 Madrid, Spain 


\section{Introduction}

The coronavirus disease (COVID-19) has impacted all countries globally and the time when society is expected to return to normal are merely gloomy prognostications that are proved to be unfounded as on today. Despite of the global herculean efforts resulting in diverse coronavirus related solutions in past year, the pandemic is growing fast and is not contained. The various businesses (including universities) had initially adapted "firefighting" approach to address the COVID19 challenges especially face to face teaching at same physical space. In a year, the pandemic situation has not been improved which means that the "new-normal" is far away. Pandemic era witnessed changes in the way the education was delivered to the students with flexible online mode replacing the traditional oncampus face to face teaching mode. However, further improving the educational experiences amid pandemic will benefit current students and may provide education sector with new practices that could revolutionize the traditional (pre-covid) way of imparting education.

For some universities it had been difficult to switch to online teaching within a short period of time. Universities have faced difficulties in establishing the information technologies infrastructure, mapping course plans to online teaching content, managing resources for online studies (like teaching material especially for laboratory courses, service learning), establishing strategies for evaluations under tight deadlines. In addition, some universities have not had the capacity to quickly switch their academic offerings online and devise strategies to continue operating during the pandemic. The transition to online teaching formats has taken time for some institutions and the rate of conversion has sometimes been lengthy. Another problem is the perceptual differences between online and traditional education among students, educators and employers which makes it hard to evaluate effectiveness of education during a pandemic. The challenge is thus to overcome the perceptual gaps as well as the supplement online learning with on-campus education, satisfying the restrictions imposed by pandemic. We believe that the universities have better opportunities to collaborate with each other to make the learning experience in the pandemic era exceptional which could become ongoing practice in "new-normal".

\section{Perceptions about online education and assessment}

In many countries, there is little agreement among researchers and educationalists about the effectiveness of online courses compared to traditional classroom teaching. Hence, the educational systems in those countries are based on face to face learning rather based on purely online teaching. For example, some studies reported that students' performance in traditional face to face learning is higher than in online learning environments (Faidley 2018; Hurlbut 2018). In contrast, other studies (Means et al. 2009; Paul and Jefferson 2019) pointed out 
that performance in online programs is at least equivalent (or better) to traditional face to face programs. Surprisingly, some researchers addressed that there are no differences in performance in online and traditional learnings (Harwood et al. 2018). However, given that the studies cited were conducted in different domains with different experimental units or sample sizes, making generalizations is difficult. There are other considerations as well in selecting full time oncampus academic programs. For instance, international students enrolled in fulltime degree courses find the full time unique experience on campus useful for their professional growth and hence do not appreciate converting their full-time degrees into an online format. There is a mixed opinion among the employers about the suitability of the online programmes for employment purposes (Seibold 2007).

There are some courses that involve a practical work (such as medical sciences, construction, navigation), and it is therefore difficult to adopt them on online platforms. The credibility of the quality of education offered through online mode and suitability for the employments will be highly questionable in the educational domains with extensive practical works. One of the studies conducted in (Acosta et al. 2018) highlighted that students preferred online learning in the laboratory course of optometry, but they are dependent on the educator. This means, the active support of teachers may make it possible to bridge the gaps in offering online education in laboratories as well.

The researchers in (Gupta et al. 2019) proposed a flexible education system that allows international students to earn educational degree by cumulating the credits from online courses offered by different universities (theoretical component) and in campus practical sessions (laboratory or research components) at any collaborative university convenient to the student.

The online courses are difficult to evaluate on the basis of student submissions which could be plagiarized. Plagiarism is a challenge for learning assessments that include the evaluation of written documents submitted by the students (example assignments). The authors in (Perkins et al. 2020) highlighted that monitoring and controlling academic dishonesty in the form of plagiarism is the biggest challenge for higher education providers. The applicability of software packages (e.g., Turnitin) to detect plagiarism is limited due to their functionality, which focuses on the recognition of text similarity. It is quite possible for students to use text spinners to reduce their chances of being caught for plagiarism. Contract fraud is another problem that requires effective software solutions. In another study it was reported that the use of a plagiarism detection tool does not provide a complete solution for the removal of plagiarism from academics (Youmans 2011).

The analysis of studies reported in preceding sections highlight that it will be difficult to organize online learning for wide spectrum of courses and it seems not to be able to meet the needs of international students of all educational domains due to varying perceptions of online courses, the laboratory-oriented nature of courses, varying experiences of universities in online education and varying technical support available to them. 


\section{Possible solution}

The possible solution to the challenges, we argue, could be to allow students to undertake on-campus courses at the university closest to their home location (referred to hereafter as collaborative university). Such an arrangement could create synergy between online education imparted by the parent university (university where student is actually enrolled) and those offered face to face by the collaborative university. This blended education (i.e., online and face to face traditional education) overcomes the learning issues that exist among the courses with extensive practical work and also bridge the perceptual differences about online courses. This is implemented through credit transfer facilities between collaborating universities who share their resources for the benefit of international students, even though they are potential competitors. It is up to the parent university to determine the level of the learning equivalent of competitive courses to the parent university courses, which is reflected in the number of credits transferred. The blended education is a value adding activity for both students and the employers (Seibold 2007).

In a recent study, Perkins et al. (2020) reported the results of a survey conducted with researchers working with United Kingdom universities. One of the major findings was that the migration to online platforms/learning during the COVID-19 period had disrupted their teaching and personal lives. The migration to the online platforms by the UK universities is reported to be a major challenge for student recruitment, market sustainability, academic labor-market, and local economies.

The rationale behind the solution proposed in commentary is to offer the best possible educational experience to the students in unexpected pandemic time. In particular, the outcomes include:

1. Minimizing the risks associated with the travel of international students to foreign countries and providing them a feeling of safety (referred to hereafter as C1).

2. Supporting the online education with the on-campus learning at the collaborating university to help international students to meet as many learning objectives as possible (referred to hereafter as $\mathrm{C} 2$ ).

3. Supporting laboratory courses that are otherwise not possible via an online mode (referred to hereafter as C3).

4. After the onset of normalcy, providing to international students the experience at the parent university on campus by offering new courses and advanced courses (such as bridge courses) (referred to hereafter as $\mathrm{C} 4$ ).

\section{Post-pandemic impacts on education}

Estimating the time when society see normalcy, is an unpredictable problem. Although even when situation becomes normal, the profound changes in the educational system must remain in place. A reduction in infection rates and the gradual lifting of restrictions may allow universities to return to normal operations, but with 
continued measures related to maintaining social distancing. The likely long lasting impact of COVID-19 is summarized below, which need to be taken under consideration while formulating academic strategies for next academic year 2021-2022.

1. Universities are likely to experience a decline in revenues. ${ }^{1}$ One of the reasons for this is that fewer international students will enroll in foreign universities this year. Quacquarelli Symonds (QS) published a report, ${ }^{2}$ which found that about $46 \%$ of the study plans of international students had been affected. Out of these international students, $47 \%$ will enroll next year, $13 \%$ will change their country preference, and $8 \%$ will drop their idea to pursue their international study plans. The actual figures could be much higher, depending on the situation of the COVID-19 in the coming days and the financial situation that results from it.

2. International students are unwilling to pay regular campus fees when enrolling for online only education. They clearly prefer the valuable experience on campus and in the classroom. Nevertheless, the plans to study abroad will be strongly influenced by the decision of the parents of the students, depending on their financial abilities, confidence, emotional aspects, and feelings of security.

3. The pandemic changes the University selection criteria of the potential students. In one such study, Cattaneo et al. (2017) accessed the impact of the financial crisis of 2008 on the university selection process of the male and female students in the Italian education system. The study was conducted for the pre-crisis period (2003-2008) and post-crisis period (2009-2012). According to the study, the critical factors that attract the students in both the pre- and post-crisis periods are the size of the university, prestige (e.g., university league tables and rankings), employability, internationalization level, and availability of scholarships. Other factors include proximity of the university to students' home countries, safety and quality/variety of educational offer (Shanka et al. 2006).

4. The universities charging higher fees in the post-crisis period will be less attractive to students because of higher financial burdens on their families. The decision-making factors used by international students to study abroad (without reference to the time of crisis) are identified in (Branco and Soares 2016). These factors include academic reputation, academic quality, cost (such as availability of scholarships), educational offer that matches their academic interests, employability, and personal recommendations.

5. There could be a local drop in enrolments in the universities that are tuition feebased (from the same countries or nearby regions such as the European Union). Universities charging higher fees in the post-crisis period will be less attractive to students due to the higher financial burden on the family (Cattaneo et al. 2017), and scholarship support offered by these universities will be one of the decisive factors for academic enrolments. In case of a prolonged lockdown, there will

\footnotetext{
1 https://www.insidehighered.com/digital-learning/blogs/learning-innovation/teaching-and-learningafter-covid-19.

${ }^{2}$ https://www.qs.com/how-is-covid-19-shaping-the-higher-education-sector/.
} 
likely be major recessions in national economies, from which it will be very difficult to recover. ${ }^{3}$ Turbulances in Job market will result in reducing the circulation of money in economy, which makes it difficult for people to support tuition fees for the professional course (for example, in Spain, the fees per credit in public institutions range between $€ 22$ and $€ 36$. ${ }^{4}$ Master's degrees have a minimum of 60 credits. This amount seems to be large enough to be economically manageable under financially limited conditions).

6. COVID-19 have strongly adversely impacted the markets, which affect the employability of the graduates, meaning that they may accept lower paid jobs to get employment after graduation..$^{5}$

\section{Collaboration implementation mechanism}

The successful implementation of collaboration between universities to cope with the situation require mechanisms based on trust, understanding and flexibility. The general process associated with the process of undertaking on-campus courses at the collaborative university is formulated as follows:

1. The student visits the website of the collaborative university and selects the courses he or she wishes to study on-campus (from the list of offered courses). Depending on the mapping of the course offered by parents and collaborative university, the requested course could be categorized as Bridge Course, Mapped Course or Advanced Course. The classification is done by parent university as per their academic policies (for instance, academic outcomes and course levels). The credits for each category could be assigned as follows:

- Bridge courses (credit transfer: 1 unit)

- Mapped courses (credit transfer: full units)

- Advanced courses (credit transfer: full units plus X units)

To facilitate the course mapping process, the partner university should provide details on courses such as credits, learning outcomes, syllabus, assessment rules, laboratory sessions involved and case studies.

2. The request for course enrollment at collaborative university is sent for approval from the parent university. The parent university will access learnings, course assessments and other factors to approve the request as either Bridge Course, Mapped Course or Advanced Course. Appropriate credits are then allocated accordingly.

3. The approved request will be transferred to the partner university which will assign a virtual admission as a visiting student.

\footnotetext{
3 https://www.forbes.com/sites/miltonezrati/2020/04/01/first-statistical-signs-of-the-covid-19-recession/\# 705f0162999e.

${ }^{4}$ https://www.educations.com/study-guides/europe/study-in-spain/tuition-fees-12571.

5 https://voxeu.org/article/impact-covid-19-education
} 
4. The partner university conducts teaching and evaluates the student. The evaluation record is shared on the same platform with both student and parent university.

G: Grade obtained (mapped or advanced course only)

$\mathrm{O}$ : Online course evaluation by the parent university ( 0 if skipped)

P: Partner university evaluation (0 if skipped).

$\mathrm{G}=\operatorname{Max}(\mathrm{O}, \mathrm{P})$.

The student has the liberty to select either or both evaluations.

Under the proposed framework, international students have the option to continue their studies (or related courses including laboratory courses) at the partner universities which are easily accessible to them being close to their country of residence (meeting outcome $\mathrm{C} 1$ and $\mathrm{C} 3$ ). In addition, international students can learn via the online mode of the parent university along with on-campus learning of related courses, (meeting condition $\mathrm{C} 2$ ) and use laboratory settings (meeting outcome C3), which otherwise would not have been possible through the pure online mode (with the exception of some virtual laboratories available for specific courses, e.g., blockchain, virtual reality). In post pandemic time, international students could attend classes in the parent university on campus and can build knowledge and skills above what they learned in a collaborative mode. Some courses on campus could be conducted like advanced summer courses or fast track courses, giving international students all learning opportunities that they missed at the parent campus (condition C4).

\section{Challenges and solutions}

There exists number of challenges in the implementation of this proposal, as explained below.

\section{Spectrum of competency differences between the universities}

The universities have wide array of offered academic programs and have different core competencies. This limits the one to one mapping between the courses of the parent and host university. The on-campus course offered by the host university could be equivalent to a bridge course (or founding course), which is seen as a preparatory course for the parent university course. This wide spectrum of competency difference between the universities increases the number of challenges as follows:

- Universities which are top ranked may not agree to engage in collaborations with direct or potential competitors to retain a competitive advantage.

- The inter-university student exchanges felicitated by collaborations should be driven by less bureaucratic processes. A significant number of international students enrolled in a university usually come from different backgrounds such as financial status, nationalities, family constraints. If, on average $40 \%$ international students apply for such collaboration then the university has to make agreements 
with $40 \%$ competing universities, which seems very difficult due to time constraints and the associated bureaucratic decision-making.

- The two universities (especially potential competitors) may have a limited consistency in their study portfolios, which limits the possibilities for collaboration.

- The collaboration request triggers the course mapping process by parent university for which collaborating university have to coordinate by sharing course learning outcomes, curricula, agreements to offer study, maintain comparable learning levels. Possibility of a larger number of requests and subjective judgements will be a key issue to resolve.

- Universities may have different documentary requirements and language certification requirements, which may contradict the admission norms established among the collaborating universities.

- The credit transfer between two institutions requires building knowledge and capacity of the college advisors and the students (Hodara et al. 2017). The credit transfer is a challenge and poses obstacles to the successful graduation of college students (Doyle 2006; Monaghan and Attewell 2015). Almost every university prefers the credit transfer, but recognition is usually not an automatic process, but involves a lengthy process of request submission and decision by the academic committee and can also mean the loss of credits.

The solution to the above challenges includes the following:

- The collaboration is established on request of the students in terms of their willingness to learn at the competing campus for some credits that are offered in the parent university. The scope of collaboration is very narrow and is restricted to offering acceptance for on-campus studies for courses approved by the parent university and the credit transfer recognized by the parent university. Hence, the competitor advantage and admission regulations do not seem to be major issues at all.

- The possibility to allow collaboration as bridge course helps students to partially learn at collaborating university and build knowledge at parent university even when there is a minimal similarity between the courses of the two potential competing universities.

- Credit verification facility on official website of the collaborative university.

\section{Agility in formulating and implementing strategies}

The occurrence of COVID-19 was sudden which forced universities to act promptly by making a transition from offline classroom-based education to fully online teaching. The collaborative agreements need to be formulated quickly in a pandemic situation, but the challenge is that no precedent ever exists to drive the process. However, the agreements could be improved over time by incorporating continuous validated learning experiences with previous agreements. These collaborations could therefore go on beyond the pandemic and help universities withstand new waves of such disasters. 
The challenge is to actually formulate strategies and implement them in the shortest possible time to establish collaborations that benefit international students. The main challenges in achieving collaborations include:

- Identifying and establishing mutual agreements on the collaboration's terms and conditions.

- Establishing the online platform to share the details (including the course learning outcomes, curricula) of the courses offered by the universities, and support for sharing the students' progress reports with the parent university. The parent university will have to map its courses with the course offers of the competing university.

- This should involve no paperwork taking into account the limitations imposed by COVID-19.

- The plan to support the collaborations should evolve as time progresses to incorporate validated learnings. However, such collaboration will be short-term and will end when a student ends his or her on-campus course. Universities may decide to extend the collaboration further on the basis of their experiences and the consolidation of good relations.

\section{Government support}

International students will face difficulties in undertaking the on-campus learning at the competing university mostly due to financial problems. The students had already paid tuition fees at the parent university and may not be motivated by the idea of collaborative learning if they are required to pay a fraction of tuition fees again. It is very unlikely that parent universities will refund the fees associated with the courses not taught on-campus or those undertaken at a competing university campus. However, under mobility exchange, the international students are either supposed to pay the collaborating university or pay only the home university. But such agreements are made well in advance on different levels of meetings and negotiations. Because the issue is between universities of different countries (and hence international) and due to the time restrictions imposed by the pandemic, the governments of the countries could play an important role by undertaking the following:

- Legislations could put an obligation on the universities to consider the free participation of international students as a contribution to society by the university.

- The government should help the various countries to recognize the knowledge obtained in each country as valid and recognized worldwide.

- The government could partially support the logistics and other expenses of international students in the form of free transportations, free enrolments and learnings.

- The government could relax rules that limit the possibility of using ICT for education and the establishment of collaboration.

- The government could provide online support for documentary verification and validation processes, administrative processes. Such processes could be allowed 
to be executed even after international students have completed on-campus learning because the lockdown may affect the timelines to execute such processes. In other words, provisional enrolments based on international student entitlements could be offered and reviewed in the future.

\section{Decision-making}

Different countries have different processes for decision-making related to university collaborations. In some countries, the state universities have to obtain the approval of the state government and, finally, of a national educational institution before they enter into collaboration, which is very time consuming. However, in other countries the individual universities have full autonomy to establish collaboration.

To cope with the challenges of establishing collaborations with minimal administrative burdens considering the time restrictions, the decision- making should include fewer discussion rounds and a smaller number of management levels. This means that the principle of subsidiarity should hold, i.e., higher management (government or regulatory authority) and should not exercise functions related to deciding on a cooperation, which can be carried out efficiently by the lower management of the education system (universities). Providing such flexibility and maintaining government support is a major challenge.

\section{Different views of online learning}

Different countries have different rules in offering online education. In countries such as India it is mandatory for every university to ask permission before offering an online degree. In some countries, the universities offer degrees in an online mode along with the traditional classroom-based mode. They also have a blended mode where classroom sessions and online sessions are combined to generate more value for international students (e.g., Hong Kong). However, international students are reluctant to enroll in online degrees because there are major differences of opinion among the stakeholders (such as the government, employers, and other universities for higher education) as to the value of the online degrees. This is perceptual thinking and with the advancement in information and communication technologies online learning clearly provides enough value. There is no consensus among researchers on the differences of performance between online and traditional face to face learning. However, the level of performance depends on the study domain and many other factors too. Eder et al. (2010) reported that there is a positive support for online degrees from the employers, but they expect the degree to be earned from a reputed university. Thus, the attitude of the employers depends on where the students have obtained their online degrees.

The uncertainties about value and future applicability of the online degrees (or degrees with online courses) will have strong levels of demotivation among international students who prefer classroom-based learning. 


\section{Conclusions}

To sum up_-given the urgent needs of innovating the educational offerings in the time of pandemic and status of research on online education to date, we suggest that it is time to look for collaborations among educational universities with the long term focus. We see two essential issues here.

1. Establishing collaboration framework and its acceptability among stakeholders including universities, employers, educators, and the government. This means that blended learning experience should not be questionable at any point of time by any stakeholder. The students should be given flexibility in selecting the universities for various courses which enhance his competencies, and he should be evaluated for the learning he processes rather the mode of learning. The perceptual gaps between online and traditional learning should be bridged by the lessons taught by pandemic.

2. The landscape is changing - there is an urgent to continue with the improvement in learning through collaborative partnerships beyond the pandemic. This will support student to take short as well as long term visiting student role across university spectrum to fill the competency gaps.

One limitation of the solution is that the universities have to agree to formulate strategies to either share small proportions of the expenditures on the basis of enrolments or to collaborate to help humanity by offering free certifications to international students. Governments could play an active role in establishing the agreements between educational entities on an international level and by providing support to international students. The COVID-19 pandemic could be seen as an opportunity to revolutionize the educational sector by leveraging the use of the online learning technologies and increasing the portfolio of academic offerings, in collaboration with other universities. COVID-19 is providing to the chance of academic institutions to formulate collaborative agreements and put them into use to gain sufficient learning to continuously innovate them. These collaborations will help students gain specialized knowledge from various universities by taking full advantage of their core competencies as the exchange student. The lessons learned after subjecting the collaborating academic policies in actual use will revolutionize the future educational offerings and knowledge management, thereby making the COVID-19 as one of the opportunities that the educationalist tapped completely.

Funding Author confirms that he did not receive any financial contributions or funding from any third party for this research.

Data availability Data sharing not applicable to this article as no datasets were generated or analyzed during the current study.

\section{Declarations}

Conflict of interest The author declares no competing interest that are relevant to the content of this article. 


\section{References}

Acosta ML, Sisley A, Ross J, Brailsford I, Bhargava A, Jacobs R, Anstice N (2018) Student acceptance of e-learning methods in the laboratory class in Optometry. PLoS ONE 13(12):e0209004

Branco Oliveira D, Soares AM (2016) Studying abroad: developing a model for the decision process of international students. J High Educ Policy Manag 38(2):126-139

Cattaneo M, Horta H, Malighetti P, Meoli M, Paleari S (2017) Effects of the financial crisis on university choice by gender. High Educ 74(5):775-798

Doyle WR (2006) Community college transfers and college graduation: whose choices matter most? Change Mag High Learn 38(3):56-58

Eder J, Smith WW, Pitts RE (2010) Exploring factors influencing student study abroad destination choice. J Teach Travel Tour 10(3):232-250

Faidley J (2018) Comparison of learning outcomes from online and face-to-face accounting courses, electronic theses and dissertations. p $3434 \mathrm{https}$ ://dc.etsu.edu/etd/3434,EastTennesseeStateUniversity

Gupta V, Chauhan DS, Hanne T (2019) MOOC learning platform development. CRC Press, Boca Raton

Harwood KJ, McDonald PL, Butler JT, Drago D, Schlumpf KS (2018) Comparing student outcomes in traditional vs intensive, online graduate programs in health professional education. BMC Med Educ 18(1):240

Hodara M, Martinez-Wenzl M, Stevens D, Mazzeo C (2017) Exploring credit mobility and major-specific pathways: a policy analysis and student perspective on community college to university transfer. Community Coll Rev 45(4):331-349

Hurlbut, A. R. (2018). Online vs. traditional learning in teacher education: a comparison of student progress. Am J Dist Educ, 32(4), 248-266.

Means B, Toyama Y, Murphy R, Bakia M, Jones K (2009) Evaluation of evidence-based practices in online learning: a meta-analysis and review of online learning studies

Monaghan DB, Attewell P (2015) The community college route to the bachelor's degree. Educ Eval Policy Anal 37(1):70-91

Paul J, Jefferson F (2019) A comparative analysis of student performance in an online versus face-to-face environmental science course from 2009-2016. Front Comput Sci 1:7

Perkins M, Gezgin UB, Roe J (2020) Reducing plagiarism through academic misconduct education. Int J Educ Integr 16(3):1-15

Seibold KN (2007) Employers' perceptions of online education, Doctoral dissertation, Oklahoma State University

Shanka T, Quintal V, Taylor R (2006) Factors influencing international international students' choice of an education destination-A correspondence analysis. J Mark High Educ 15(2):31-46

Youmans RJ (2011) Does the adoption of plagiarism-detection software in higher education reduce plagiarism? Stud High Educ 36(7):749-761 